Voix et Images

voixetimages

\title{
Table des matières du volume IX
}

Volume 9, numéro 3, printemps 1984

Monique Bosco

URI : https://id.erudit.org/iderudit/200496ar

DOI : https://doi.org/10.7202/200496ar

Aller au sommaire du numéro

Éditeur(s)

Université du Québec à Montréal

ISSN

0318-9201 (imprimé)

1705-933X (numérique)

Découvrir la revue

Citer ce document

(1984). Table des matières du volume IX. Voix et Images, 9(3), 210-211.

https://doi.org/10.7202/200496ar d'utilisation que vous pouvez consulter en ligne.

https://apropos.erudit.org/fr/usagers/politique-dutilisation/ 


\section{TABLE DES MATIÈRES DU VOLUME IX}

ANDRÈS, Bernard:

BARROIS-GEROLS, Jacqueline:

BISHOP, Neil B.:

BLODGETT, E.D.:

BOIVIN, Aurélien:

BONENFANT, Joseph:

BROCHU, André:
«Le syndrome Ronfard», 1, pp. 163-165;

«L'opéra-punk du bon barbare», 2 ,

pp. 165-166;

«Imaginaire inuit et théâtre pour enfant:

l'Umiak», 3, pp. 169-170.

«L'image du roman qubécois en France», 2,

pp. 93-102.

«Distance, point de vue, voix et idéologie dans les Fous de Bassan d'Anne Hébert», 2 , pp. 113-129.

«Le mythe des ethnies dans le roman de l'Ouest canadien: du père dominateur et la mère conciliatrice», 1, pp. 119-137. «Bibliographie de Guy Dufresne» (en collaboration), 1, pp. 59-81.

«La poésie de Monique Bosco, une quête de justice», 3, pp. 13-21.

«De la mer à la mer», 1, pp. 141-150;

«François Charron, etc.», 2, pp. 145-154; «Portrait de Minerve peint par elle-même, entrevue avec Monique Bosco", 3, pp. 5-12; «Flamboyants et profonds», 3, pp. 155-164.

CAMPAGNOLI, Ruggero: «Figures et fantasmes de l'industrie dans l'Influence d'un livre», 2, pp. 131-142.

CHASSAY, Jean-François: «Notre première revue: l'Opinion publique (1870-1883), 2, pp. 131-142.

CLICHE, Elène:

DUCIAUME, Jean-Marcel:

DUPRIEZ, Bernard:

DUQUETTE, Jean-Pierre:

ESCOMEL, Gloria:

FADIN, Max:

GAGNON, Claude-Marie: GALLAYS, François:

GOLDIN, Jeanne:
«Emmanuel Cocke, l'amphigouri ou les esquives de la stupeur», 3, pp. 85-101. «Encre et poème, entrevue avec Roland Giguère», 2, pp. 7-17.

«Ha, Gauvreau! ou De la scansion», 1, pp. 97-102.

«Louise Gadbois 'revisited'», 1, pp. 167-169;

"L'oeuvre étrange de William Kurelek», 2, pp. 167-169;

"Vous avez dit AANFM?», 3, pp. 171-173.

«Monique Bosco, 1'iconoclaste», 3, pp. 47-54. "Giguère humaniste?», 2, pp. 19-45.

«La censure au Québec», 1, pp. 103-117. «Les corps scellés. Analyse de trois romans de Monique Boscon, 3, pp. 35-45.

«La passion selon M.B.», 3, pp. 23-33. 
HAYWARD, Annette:

LAMOTHE, Jacques:

LÉVESQUE, Gaétan:

MARCHAND, Hélène:

MICHON, Jacques:

MINASSIAN, Chaké: NISSIM, Liana:

PATERSON, Janet:

PAVLOVIC, Myrianne:

PIETTE, Alain:

ROBERT, Lucie:

SAINT-MARTIN,

Fernande:

SÖDERLIND, Sylvia:

THÉRIEN, Gilles:

VANASSE, André:

WHITFIELD, Agnès:
«Ả propos d'Un matriarcat en procès», 1, pp. 155-157.

«Le récit télévisuel et son écriture», 1, pp. 7-27;

«Une affinité sélective entre l'auteur et la réalisation, entrevue avec Guy Dufresne», 1, pp. 28-37.

"La revue des revues», 1, pp. 177-181;

2, pp. 177-181; 3, pp. 189-194.

«Cap-aux-Sorciers: un archétype du téléroman québécois», 1, pp. 39-58.

«La quête du sens», 1, pp. 151-153;

«L'édition au Québec de 1764 à 1974», 2,

pp. 155-159;

«Figures du roman québécois», 3, pp. 165-168.

«Bilan», 3, pp. 179-185.

«'Mésaventure'»: engendrement du poème et mythographie», 2, pp. 61-73.

«L'envolée de l'écriture: les Fous de Bassan d'Anne Hébert», 3, pp. 143-151.

«Bibliographie de Monique Bosco», 3, pp. 57-84.

«Les langues à Papineau: comment le texte national se fait littérature», 3, pp. 113-127. «Bibliographie de Guy Dufresne» (en collaboration), 1, pp. 59-81.

«De la critique formaliste à la sémiologie visuelle», 2, pp. 85-95.

«Hubert Aquin et le mystère de l'anamorphose», 3, pp. 103-113.

«Maria Chapdelaine: le tapuscrit manquant», 1, pp. 171-173;

«Bonheur d'occasion: Claude Fournier lecteur», 2, pp. 171-173;

«De Au clair de la lune (André Forcier) à 'sa chandelle est morte'», 3, pp. 175-178. «Les fous, les demeurés, les rêveurs...», 2, pp. 161-164.

«Gabrielle Roy et Gérard Bessette: quand l'écriture rencontre la mémoire», 3, pp. 129-141. 